\title{
PARQUE GOVERNADOR JOSÉ ROLLEMBERG LEITE, ARACAJU (SE): UMA ANÁLISE DA PERCEPÇÃO DE SEUS VISITANTES
}

\author{
Márcia Regina Barreto ${ }^{1}$ \\ Laura Jane Gomes ${ }^{2}$ \\ Carina Angélica dos Santos ${ }^{3}$ \\ Márcio Roberto Cardoso da Silva ${ }^{4}$ \\ Gregório Guirada Faccioli ${ }^{5}$
}

\begin{abstract}
Resumo: No Parque Governador José Rollemberg Leite está inserido o último remanescente de floresta de Mata Atlântica da cidade de Aracaju. Este estudo teve como objetivo analisar a percepção dos visitantes sobre o referido parque e sobre a vegetação presente neste espaço. Foram realizadas entrevistas padronizadas com análise quali-quantitativa dos resultados. O principal fator motivacional à visitação do parque é o lazer/diversão; a vegetação do parque foi considerada importante para a maioria, porém muitos não souberam informar de qual ecossistema é a vegetação predominante. Verificou-se a presença de laços afetivos dos entrevistados, moradores das proximidades, referentes a lembranças de infância, como também pautados nas atitudes e valores relacionados ao pertencimento ao lugar.
\end{abstract}

Palavras-chave: Parques Urbanos; Áreas verdes; Gestão Ambiental; Topofilia.

2 Universidade Federal de Sergipe E-mail: laurauturi@gmail.com

3 Universidade Federal de Sergipe. E-mail: profcarina@yahoo.com.br

${ }^{4}$ Faculdade Estácio de Sergipe. E-mail: marciorobert1978@hotmail.com.br

5 Universidade Federal de Sergipe. E-mail:gregorioufs@gmail.com 


\section{Introdução}

Um ambiente urbano dotado de áreas verdes agrega valor à cidade e melhora a satisfação e o bem estar social, pois podem trazer benefícios, como a melhoria da qualidade do ar, diminuição da sensação térmica, além de propiciar espaço para o desenvolvimento do lazer e interação social (SANTOS; GOMES; GOMES; SANTANA, 2013).

Os parques urbanos são espaços dotados de cobertura vegetal e devem oferecer aos cidadãos opções de lazer, diversão, desenvolvimento de atividades físicas e contato com a natureza (DORIGO; LAMANO-FERREIRA, 2015). Entretanto para que eles funcionem com qualidade é necessário atender aos anseios e necessidades dos visitantes, mantendo a conservação ambiental, o que envolve planejamento e gestão dessas áreas.

Deste modo, os estudos sobre percepção são relevantes no processo de planejamento e gestão dos parques urbanos, pois as informações disponibilizadas pelos atores sociais podem contribuir nas tomadas de decisões e subsidiar ações educativas voltadas à conservação ambiental. É possível constatar a percepção de um determinado público por meio de instrumentos de pesquisa e, com os resultados, fomentar projetos e atividades relacionadas ao meio ambiente com base na realidade desse público (MATOS; GOMES, 2011).

Em Aracaju, os moradores que dedicam um tempo para o lazer preferem praticá-lo em áreas naturais, como praias, praças e áreas verdes, o que indica um forte elo desses com o ambiente natural no espaço urbanizado (FRANÇA; SANTOS; GOMES, 2013). Em relação às áreas verdes do município de Aracaju, verifica-se que existe um déficit, pois apenas $14,8 \%$ dessas áreas são classificadas como pertencentes àqueles tipos de áreas verdes de acesso ao público (SANTOS; GOMES; FERREIRA, 2016).

O Parque Governador José Rollemberg Leite, em Aracaju (SE), também conhecido como Parque da Cidade, está inserido em uma Unidade de Conservação, a Área de Proteção Ambiental - APA Morro do Urubu. Essa área abriga o último remanescente florestal de Mata Atlântica da cidade, e apesar de possuir vários estudos acadêmicos (ARAÚJO; FREITAS, BRAGHINI, 2011; SANTOS; GOMES; GOMES; SANTANA, 2013), verifica-se que existe uma carência de estudos, principalmente no que se refere à percepção dos visitantes com relação ao parque e à percepção sobre a vegetação do bioma Mata Atlântica.

Sendo assim, este trabalho se justifica por preencher essa lacuna existente que está relacionada à participação social nos processos de gestão ambiental, pois a análise da percepção dos visitantes sobre essa área poderá disponibilizar informações relevantes para que os gestores desenvolvam políticas públicas voltadas aos anseios e necessidades da sociedade e à conservação ambiental da área.

Este estudo apresentou como pressupostos: a importância atribuída ao parque pelos visitantes está relacionada primeiramente ao lazer e à diversão 
devido à presença de atrativos construídos no parque, como o zoológico e o teleférico; os visitantes consideram a vegetação importante para o contato com a natureza, mas desconhecem que se trata do último remanescente de Mata Atlântica da cidade; os visitantes, moradores das proximidades do parque, apresentam um elo afetivo com o lugar.

Sendo assim, o presente estudo teve como objetivo analisar a percepção dos visitantes sobre o Parque Governador José Rollemberg Leite, bem como sobre a vegetação presente neste espaço (Mata Atlântica).

\section{Área de estudo}

O Parque Governador José Rollemberg Leite, também conhecido como Parque da Cidade, foi criado em $1979 \mathrm{com}$ a função de proporcionar lazer e diversão, como também contato com a natureza aos frequentadores. Ele possui uma área de 750 mil metros quadrados e a sua estrutura é composta por parque infantil, campos de futebol, pomar, lago artificial, vias de circulação e um zoológico (GRAÇA, 2005).

Ele abriga em seu interior o último remanescente florestal de Mata Atlântica da cidade, então em 1993 foi criada a Área de Proteção Ambiental Morro do Urubu (Figura 1), com a função de servir como zona de amortecimento do parque que além do espaço de lazer, abriga o último remanescente de vegetação de Mata Atlântica da cidade de Aracaju.

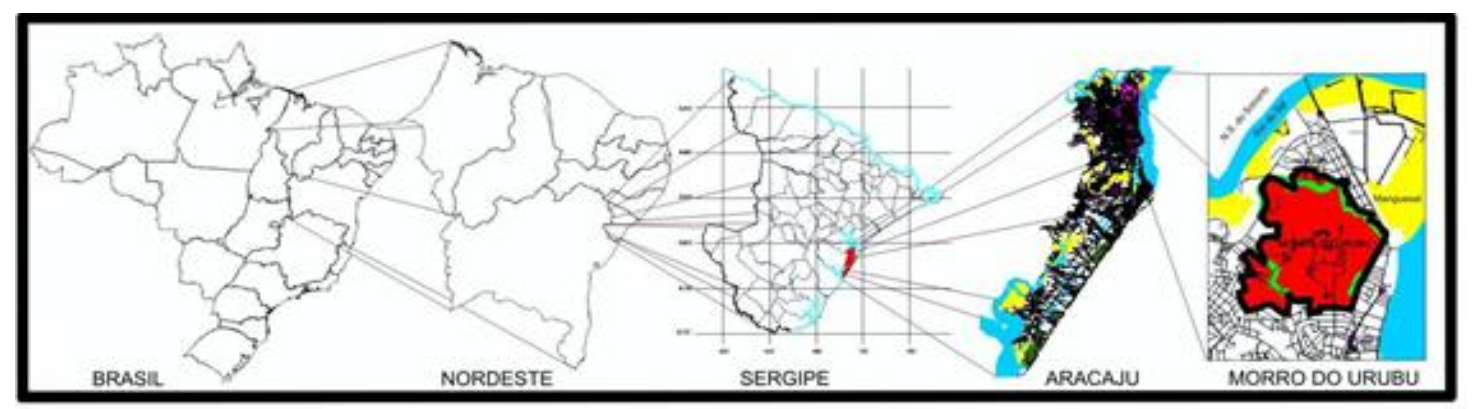

Figura 1: Localização da Área de Proteção Ambiental Morro do Urubu, Aracaju. Fonte: (MATOS; GOMES, 2011), adaptação da Base Cartográfica PMA/SEPLAN (2005).

Essa APA foi estabelecida pelo Decreto 13.713 de 15 de junho de 1993 e possui uma área com 213,8724 ha (SERGIPE, 1993). Ela limita-se ao norte com o rio do Sal, ao sul com o rio Sergipe e à Oeste com áreas urbanizadas da cidade (SANTOS; GOMES; GOMES; SANTANA, 2013).

O Parque da Cidade contribui para a conservação da biodiversidade in situ (nativas) e ex situ (espécies exóticas, muitas encontradas no zoológico). A área da Mata Atlântica abriga espécies de vegetação nativa com catalogação de 138 espécies, 110 gêneros e 57 famílias, além de outras ainda não catalogadas, contendo inclusive algumas espécies ameaçadas de extinção, Revbea, São Paulo, V. 14, № 2: 328-342, 2019. 
como o Pau-brasil (Paubrasilia echinata Lam. - Gagnon, H.C.Lima \& G.P.Lewis) e o Ingá (Inga edulis Martius) (SILVA; SOUZA, 2011).

Convém ressaltar que a APA Morro do Urubu é administrada pela Secretaria Estadual do Meio Ambiente e dos Recursos Hídricos (SEMARH), enquanto que o Parque Governador José Rollemberg Leite é administrado pelo Departamento de Desenvolvimento Agropecuário de Sergipe - DEAGRO. Estudo realizado por Matos; Gomes (2011), constatou que a gestão dessas áreas por esses órgãos é prejudicada pelo entrave de desarticulação entre eles e pela própria prefeitura de Aracaju, que não reconhece a importância da área em importantes documentos, a exemplo do Plano Diretor do município.

\section{Coleta e análise das informações}

O método geral de abordagem foi o fenomenológico, com característica quali-quantitativa, com desenvolvimento através de pesquisa bibliográfica, documental e entrevistas semiestruturadas (RODRIGUES, 2006). O projeto de pesquisa passou pelo comitê de ética da Plataforma Brasil.

Foram realizadas 300 entrevistas entre os meses de abril a novembro de 2016, na entrada do zoológico, com alternação em horários e dias da semana e finais de semana. O parque não possui dados atualizados sobre o número de visitações mensais. Sendo assim, optou-se pela amostragem não-probabilística por julgamento (ALENCAR,1999). Os critérios adotados foram: idade acima de 16 anos, visitantes que moram no entorno do parque, que moram em outros bairros de Aracaju e visitantes que residem em outras localidades fora de Aracaju.

A aplicação das entrevistas foi realizada por meio de formulários contendo perguntas abertas e fechadas e foram aplicadas de forma presencial e preenchidas pelo próprio entrevistador (pesquisador e dois auxiliares). As perguntas fechadas foram sobre: local de residência fixa dos visitantes, sexo, forma de deslocamento de casa até o parque, grau de escolaridade, idade, número de dependentes, principal ocupação, renda mensal, quantidade de visitas ao parque por ano e principal fator motivacional à visitação. Foi solicitado também que os entrevistados classificassem de 1 a 5 (sendo 1- ruim, 2- regular, 3- bom, 4- muito bom e 5- excelente) a beleza cênica, o zoológico, o teleférico, o Mirante da Santa, os equipamentos de lazer, a vegetação nativa do parque, a limpeza do parque, a disposição das lixeiras, a segurança no parque e a receptividade aos visitantes. Outra pergunta foi se os equipamentos e a infraestrutura do parque atendiam às necessidades do visitante (sim/não), pedindo que justificasse a resposta.

As perguntas abertas foram: "O que você considera mais importante no parque?", "Em sua opinião o que precisaria melhorar no Parque?", "Em sua opinião qual a importância da vegetação nativa presente no parque?", "Você sabe o nome da vegetação predominante no parque?", "Descreva o que vem a sua mente quando pensa no Parque da Cidade."

revista brasileira educação ambiental 
No processo de tabulação e análise dos resultados, as perguntas fechadas foram codificadas e tabuladas através do software SPSS v15 (Statistical Package for the Social Sciences). As respostas das perguntas abertas foram submetidas a um agrupamento das palavras em categorias de acordo com o significado do núcleo central das frases (BARDIN, 2011), com posterior codificação e tabulação dos dados através do mesmo software, o SPSS v15. A análise ocorreu de forma interpretativa, com destaque de alguns trechos das respostas referentes às perguntas abertas, quando necessário.

\section{Perfil dos entrevistados}

Os visitantes que contribuíram para o desenvolvimento desta pesquisa, após a aplicação do questionário, foram classificados em três grupos para facilitar a identificação do local de residência fixa, como segue abaixo:

- Grupo 1, correspondeu aos visitantes que residem no entorno do parque, nesse grupo foram considerados os bairros Industrial, Porto Dantas e Coqueiral, que correspondeu a um percentual de $23 \%$ dos entrevistados;

- Grupo 2, foi formado pelos visitantes que residem em outros bairros de Aracaju, Nossa Senhora do Socorro e São Cristóvão, devido à proximidade entre essas cidades elas foram agrupadas em uma única classe. A maioria dos entrevistados pertenceu a esse grupo, que apresentou um percentual de 51,7\%;

- Grupo 3, representou os visitantes que residem em outras cidades do estado de Sergipe, turistas nacionais e internacionais, que correspondeu a $25,3 \%$ dos entrevistados.

Dos entrevistados, $52 \%$ corresponderam ao sexo feminino. O grau de escolaridade com maior incidência entre os entrevistados correspondeu ao ensino médio completo, $52,3 \%$; seguido pelo ensino médio incompleto, $17,7 \%$; ensino superior completo, $12,0 \%$; e ensino superior incompleto, $6,3 \%$. Pessoas com ensino fundamental (completo e incompleto) corresponderam a 9,7\% e pós-graduação (completo e incompleto), $2 \%$.

A maior parte dos entrevistados encontra-se na faixa etária entre 16 a 29 anos, 39,7\%, seguidos pelos que se encontram entre 30 a 39 anos, $36,7 \%$, e 40 a 49 anos, $16,7 \%$. A faixa etária com menor percentual entre os entrevistados foi a de pessoas com idade acima de 50 anos, $7 \%$. Com relação ao número de dependentes, $26,7 \%$ dos entrevistados afirmaram não ter dependentes; $49,7 \%$ possuem de 1 a 2 dependentes; $22,0 \%$ possuem de 3 a 5 dependentes; $1,3 \%$ entre 6 e 7 dependentes; e 0,3\% dos entrevistados possuem de 8 a 10 dependentes.

A maioria dos visitantes que participaram da pesquisa possui emprego 
estudantes; cuidadores do lar, 10,3\%; aposentados, 3\%; pensionistas, 0,3\%; e outros $9 \%$.

O parque recebe pessoas de todas as classes sociais, sendo que a renda mensal dos entrevistados com maior incidência foi de 1-3 salários mínimos, o que representou um percentual de $45,1 \%$; os que recebem até 1 salário, $11,9 \%$; de 4 a 5 salários, $10,1 \%$; e 6 a 10 salários, $1,7 \%$. Outros afirmaram ser dependentes, $30,7 \%$.

A forma de deslocamento mais citada pelos visitantes entrevistados para se deslocarem de sua residência fixa até o parque foi o veículo motorizado próprio, equivalendo a $58 \%$ das respostas; a segunda opção foi o transporte coletivo, 21,5\%; a pé, 17,4\%; bicicleta, $1,3 \%$; ônibus escolar, $0,6 \%$; e outros, $1 \%$.

O parque é mais frequentado por pessoas que residem no entorno e $49,3 \%$ deste grupo afirmaram que realizam de 3 a 6 visitas ao ano. Entre os moradores de outros bairros da cidade, a maioria, 32,9\%, respondeu que passam mais de um ano sem visitar o parque, e entre os turistas, a maioria, $55,3 \%$, afirmaram que estavam visitando pela primeira vez.

\section{Percepção dos entrevistados sobre vegetação e sobre a Mata Atlântica do parque}

A identificação do que os visitantes consideram mais importante dentro do parque, de acordo com os resultados da entrevista, está relacionada principalmente à contemplação da natureza, correspondendo a $64,7 \%$ das respostas. Quando associada, pelos entrevistados, a outros aspectos como tranquilidade, seguranças, convívio social e lazer/diversão, a contemplação da natureza representou um percentual de $69,4 \%$. Os entrevistados citaram também lazer/diversão, 5,0\%; tudo ou nada, 3,0\% e 0,7\%, respectivamente; e outros, $8 \%$ (Tabela 1 ).

Tabela 1: O que o visitante considera mais importante dentro do Parque Governador José Rollemberg Leite. Aracaju (SE).

\begin{tabular}{lc}
\hline Respostas & Porcentagem \\
\hline Contemplação da natureza & $64,7 \%$ \\
Contemplação da natureza e tranquilidade (paz e harmonia) & $1,0 \%$ \\
Contemplação da natureza e segurança & $1,3 \%$ \\
Contemplação da natureza e convívio social & $0,7 \%$ \\
Contemplação da natureza e lazer/diversão & $1,7 \%$ \\
Nada & $0,7 \%$ \\
Tudo & $3,0 \%$ \\
Lazer/ diversão & $5,0 \%$ \\
Outros & $8,0 \%$ \\
\hline
\end{tabular}

Fonte: pesquisa 
O contato com a natureza é interpretado como o principal item de atração também em outros parques localizados na região Sul do país, segundo Hidelbrand (2001), nos parques de Curitiba, 66,8\% dos entrevistados fizeram menção ao contato com a natureza como a principal atração.

O Parque Governador José Rollemberg Leite abriga um importante remanescente de Mata Atlântica que precisa ser preservado, sendo assim, o conhecimento a respeito do significado dessa vegetação para os visitantes é relevante, deste modo, eles foram questionados sobre a importância da vegetação presente nesse espaço (Figura 2).

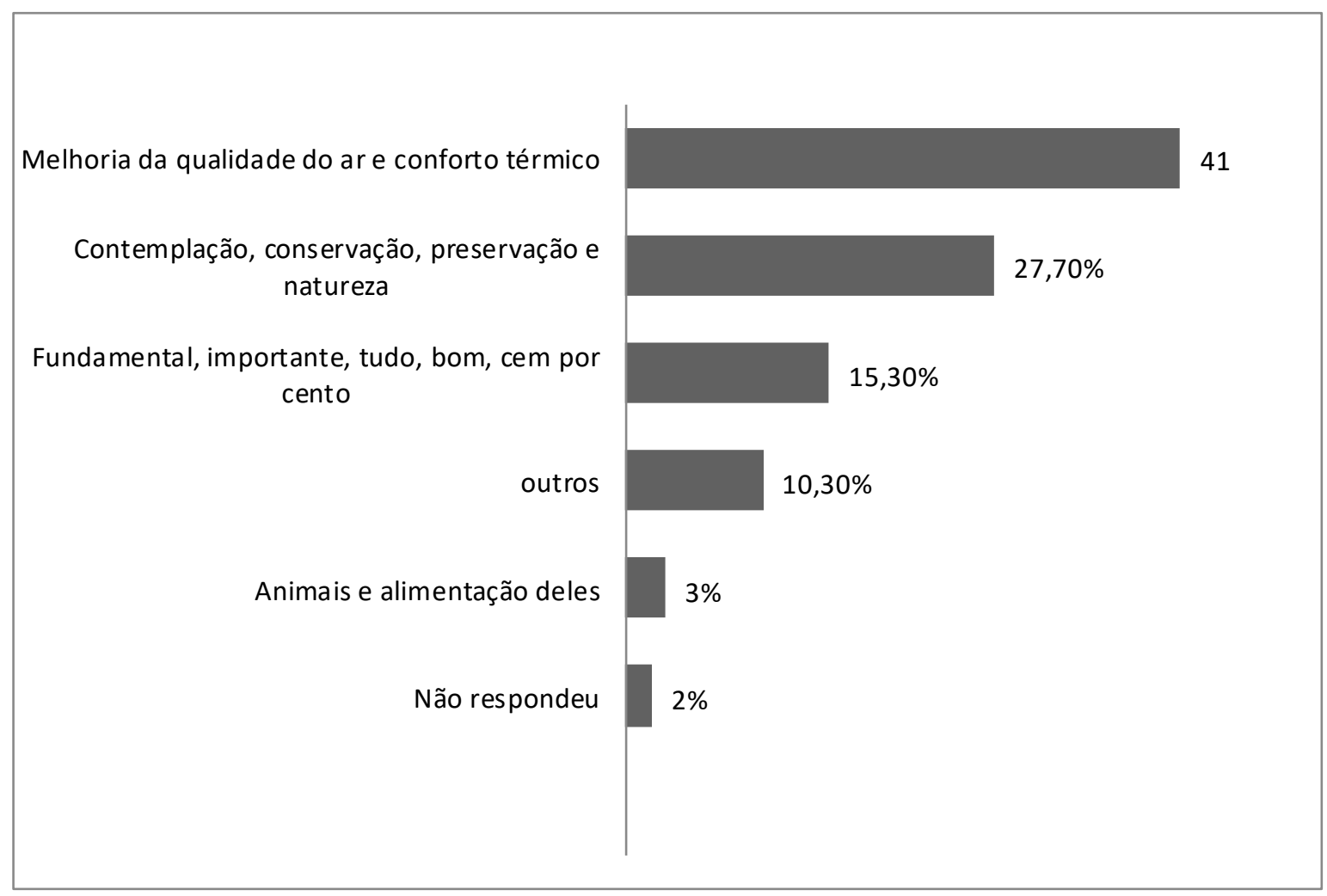

Figura 2: Importância da vegetação do Parque Governador José Rollemberg Leite para os entrevistados, Aracaju - SE. Fonte: pesquisa. 
$\mathrm{Na}$ região central de Mandirituba - Paraná, $73 \%$ dos entrevistados demonstraram ter conhecimento com relação aos benefícios propiciados pelas árvores no ambiente urbano, sendo que $80 \%$ dos moradores disseram que a arborização da cidade contribui para a redução da poluição e redução do calor, o que melhora a qualidade do ar (HO et al., 2015).

Em Belém um estudo teve como principal objetivo avaliar a percepção de moradores da cidade com relação à arborização viária com manga (Mangifera indica L.). De acordo com os resultados, moradores apresentaram alta percepção sobre a influência das árvores no microclima, sombreamento e purificação do ar, eles souberam reconhecer como benefícios propiciados por essas árvores a "qualidade de vida, purificação do ar, sombra, abrigo e alimento para avifauna e embelezamento da rua" (SILVA; BATISTA; BATISTA, 2015). No estudo realizado no município de Alegre (ES), a população também considerou importante a arborização urbana e seus benefícios à qualidade de vida (SOUZA; CARDOSO; SILVA, 2013).

Os entrevistados foram instigados a classificar a vegetação do parque como: 1- ruim, 2- médio, 3- bom, 4- muito bom ou 5- excelente. Sendo assim, ela foi classificada pela maioria, $73 \%$, como excelente. Eles também foram questionados sobre o nome da vegetação presente no parque, sendo que apenas $17,7 \%$ dos entrevistados responderam corretamente que se trata de uma área de vegetação nativa da "Mata Atlântica".

\section{Percepção dos entrevistados sobre os atrativos do parque, os equipamentos de lazer, segurança e receptividade}

Os entrevistados foram estimulados a falar abertamente sobre seu pensamento e sentimentos em relação ao parque a fim de se verificar 0 significado que esse espaço representa para eles. Deste modo, 42,3\% mencionaram lazer/diversão; 40\% citaram tranquilidade (paz, sossego, relaxamento, bem-estar); $34,6 \%$ responderam contemplação da natureza (preservação, área verde); $3,3 \%$ afetividade; $0,3 \%$ segurança/infraestrutura; $0,3 \%$ citaram nada como resposta; e 9,7\% deram respostas diversificadas.

Com relação ao fator motivacional à visitação, $57,3 \%$ informaram que frequentam o parque em busca de lazer e diversão; a visitação ao zoológico foi a segunda opção mais citada, correspondendo a 18,3\%; contemplação da natureza, 16,3\%; atividade física, 3,3\%; atividade escolar, $1 \%$; e outros 3,7\%. Quando os entrevistados foram questionados sobre a satisfação em relação ao parque, $54,7 \%$ responderam que o parque atende as suas expectativas e necessidades.

De acordo com Tuan (1980), a cultura pode influenciar a percepção, dessa maneira pode haver diferenças de atitudes entre o visitante e o nativo de modo que focalizem aspectos diferenciados do meio ambiente. Nesse sentido, vale ressaltar que entre os moradores que residem no entorno do parque (Grupo 1), a maioria considerou que o mesmo não atende as suas expectativas e necessidades. Em relação aos grupos 2 e 3, que são os moradores de outros 
bairros da cidade e os turistas, respectivamente, a maioria respondeu que sim, ou seja, que o parque atende às necessidades dos visitantes. Esse resultado pode ser devido à complexidade na visão das pessoas que residem no entorno do parque que, como enfatiza Tuan (1980), devido a sua imersão na totalidade de seu meio, ou seja, de acordo com as suas expectativas, esperam que o parque ofereça algo a mais, que atenda às suas necessidades em relação à carência de área de lazer existente na comunidade.

A maioria dos entrevistados considerou a beleza cênica do parque excelente, o zoológico bom, o teleférico excelente, o Mirante da Santa obteve uma classificação como bom e excelente, com o mesmo percentual, e os equipamentos de lazer foram considerados bons.

Em estudo realizado nos parques de Curitiba, os usuários justificaram que concordam com a continuidade de investimentos em parques, pois eles proporcionam opções de lazer e aumentam a qualidade de vida dos cidadãos. Os resultados demonstraram ainda que esse tipo de investimento gera um alto lucro social para a população (HILDEBRAND, 2001). Entre os que se apresentaram insatisfeitos, as principais justificativas estavam relacionadas à necessidade de melhorias, como instalação de mais banheiros, reforma no zoológico, concerto de bancos quebrados, além de outras melhorias na infraestrutura do parque.

Alguns visitantes relataram que o parque carece de equipamentos destinados ao lazer/diversão. Nesse sentido, vale ressaltar que o parque está localizado dentro da Área de Proteção Ambiental Morro do Urubu, uma unidade de conservação que deve compatibilizar o uso recreativo, visitação e lazer condicionado ao uso sustentável.

A segurança foi considerada ruim pela maioria dos visitantes entrevistados, provavelmente esse resultado deve-se ao conhecimento dos usuários sobre os constantes assaltos na área. A preocupação de visitantes com relação à falta de segurança foi verificada também no estudo realizado no parque da Cidade Mãe Bonifácia, Cuiabá-MT, em que os entrevistados mencionaram sensação de insegurança dentro do parque (BARROS; MUSIS; HORNICK, 2010).

A receptividade no parque também foi considerada ruim, pois a maior parte dos entrevistados afirmou sentir necessidade de pessoas dentro do parque disponíveis a prestar informações.

Nos relatos referentes às questões abertas foi possível perceber que a maioria dos visitantes apresenta preocupação com relação aos animais nos recintos (cativeiros), houve citações sobre verificação de maus tratos com os animais, falta de alimentos, recintos pequenos e com mau cheiro (Quadro 1). 
Quadro 1: Relatos das questões abertas sobre o zoológico do Parque Governador José Rollemberg Leite para os entrevistados, Aracaju (SE). Fonte: pesquisa.

"... achei que os animais são maltratados" (Grupo 2, ent. 271).

"o tratamento dos animais, acho que deveriam ter mais cuidado..." (Grupo 3, ent. 5).

"... os bichos parecem não ser muito cuidado, os macacos ficam no sol" (Grupo 2, ent. 269).

"os animais, tem poucos, estão mal tratados" (Grupo 2, ent. 119).

“... tratamento, muito magros, não são bem cuidados" (Grupo 1, ent. 209).

"colocar os animais em locais frescos, os macacos ficam no calor, cuidar melhor deles (Grupo 2, ent. 51).

"... tratar melhor os animais, tem jaulas com cheiro ruim" (Grupo 1, ent. $101)$.

"... o zoológico, deveria ser mais limpo, as jaulas, algumas têm mau cheiro" (Grupo 2, ent. 35).

"cuidado com os animais, tem jaulas com mau cheiro..." (Grupo 3, ent. 154)

"o cuidado com o animais, uma jaula com fedô,...(Grupo 2, ent. 164)

"os animais estão fedorentos" (Grupo 2, ent. 230).

"o tratamento com os animais, muitos estão tristes, quietos..." (Grupo 1, ent. 203).

"a limpeza das jaulas, os animais estão tristes" (Grupo 1, ent. 108).

"tratamento dos animais e as jaulas, parecem solitários" (Grupo 3, ent. 144).

"cuidado com os animais,..., animais tristes" (Grupo 3, ent. 72).

"os animais, têm poucos, e estão mal tratados, tristes" (Grupo 1, ent. 61).

“... vemos que os animais estão estressados" (Grupo 2, ent. 67).

"percebemos que os animais deveriam ter mais aconchego, os recintos maiores, mais espaço" (Grupo 2, ent. 250).

"... achei as jaulas pequenas" (Grupo 3, ent. 11).

“... o leão está magro, pouco espaço" (Grupo 3, ent. 93).

“... ter mais alimentos, cuidado com os animais..." (Grupo 1, ent. 73).

"... um zelo melhor, os que têm tão passando maus tratos, magros" (Grupo 2, ent. 190).

"... tem que alimentar melhor os animais, limpeza das jaulas" (Grupo 1, ent. 210).

"... cuidado com os animais, não tem fiscalização, crianças e adultos jogando coisas nos animais" (Grupo 1, ent. 114).

Outro aspecto que merece destaque com relação ao zoológico e aos equipamentos de lazer do parque é o trajeto do teleférico, pois ele adentra na área de Mata Atlântica e passa por cima do zoológico, sendo assim, sua 
localização pode causar desconforto aos animais nos horários de pico de uso desse equipamento, tanto no ambiente natural, quanto nos cativeiros. Situação semelhante ocorre no Parque do Sabiá em Uberlândia. Nos estudos de Mazzei, Colesanti e Santos (2007), ressalta-se que a localização do jardim zoológico dentro do parque não é recomendável, visto que a alta frequência de visitação pode provocar estresse nos animais. Uma solução viável para o trajeto do teleférico do Parque Governador José Rollemberg Leite seria a utilização das laterais das vias asfaltadas no interior do parque.

\section{Percepção dos visitantes sobre o parque: laços afetivos}

A presença de laços afetivos com a área apareceu de forma direta nos relatos referentes às lembranças de infância, à presença de amigos e familiares e aconchego na área (Quadro 2).

Quadro 2: Emoções captadas nos relatos dos entrevistados do Parque Governador José Rollemberg Leite para os entrevistados, Aracaju (SE). Fonte: pesquisa.

"lembro de infância, passei muito tempo aqui, minha visão de infância, era muito bom." (Grupo 2, ent. 244).

"lembro do tempo de criança, o parque era melhor, estava novo, mais animais, vinha brincar com os amigos." (Grupo 1, ent. 111).

"é um lugar agradável de infância com os pais desde criança,... erámos amigos e familiares" (Grupo 1, ent. 41).

"tranquilidade, sossego. Gosto de vir e ficar olhando os animais, sentar e descansar um pouco, relaxa a gente, lembro muitas coisas boas, venho muito com a família" (Grupo 1, ent. 17).

"lembranças boas, trazer a família para passear, jogar bola..." (Grupo 1,, ent 44).

As respostas dos entrevistados perante o meio ambiente podem ser estéticas, táteis ou sentimentais e variarem em intensidade, sutileza e modo de expressão (TUAN, 1980). Neste estudo verificou-se que os visitantes do parque apresentaram um sentimento de respeito e afeição com um lugar onde se sentem bem e se identificam. A análise das respostas dos entrevistados durante todo o estudo demonstra presença de laços afetivos, tanto nos relatos de infância, quanto nos referentes aos sentimentos de prazer e satisfação em contato com a natureza (Quadro 3). 
Quadro 3: Sentimentos de prazer e satisfação dos entrevistados quando em contato com a natureza no Parque Governador José Rollemberg Leite para os entrevistados, Aracaju (SE).

Fonte: pesquisa.

"me sinto bem, sentir a natureza de perto, as árvores, andar, conversando,..., onde estão os animais...” (Grupo 1, ent. 29).

"penso em beleza, ver os animais, paz, clima, sossegado,..., tirar o barulho, dá melhor saúde" (Grupo 2, ent. 38).

"lazer, paz, me sinto muito bem..." (Grupo 1, ent. 16).

"sinto feliz, diversão, alegria" (Grupo 2, ent. 39).

"lazer, muita coisa boa, distração, coisas que não tem em outros lugares" (Grupo 2, ent. 47).

“as crianças descansar, lugar calmo,..., é bom vim, eu gosto" (Grupo 2, ent. 228).

“lazer, lugar bonito,..., harmonia, tranquilidade" (Grupo 3, ent. 188).

Em alguns relatos transparecem emoções captadas pelas pessoas que remetem a bem-estar, alusão ao divino, religiosidade ou sentimentos mais profundos, percorrendo o campo da espiritualidade quando em contato com o meio ambiente. Os relatos podem ser verificados no Quadro 4.

Quadro 4: Emoções que remetem ao bem estar e religiosidade no Parque Governador José Rollemberg Leite para os entrevistados, Aracaju (SE). Fonte: pesquisa.

"liberdade, saúde, tranquilidade, melhora a mente da gente" (Grupo 2, ent. 276).

"vida futura, paraíso, o futuro prometido, Deus" (Grupo 1, ent. 76).

"a natureza de Deus, venho passear e agradecer a Deus por tudo" (Grupo 2, ent. 157).

De acordo com Tuan (1980), a percepção humana sobre o meio ambiente pode ir além do que os órgãos dos sentidos podem captar. Os entrevistados citaram que gostam de estar no parque, sentem tranquilidade, paz e harmonia, relembram momentos da infância ou fazem alusão a Deus e ao paraíso. Esses sentimentos de aconchego que se manifestam nos indivíduos quando em contato com a natureza são benéficos, visto que essas sensações favorecem o desenvolvimento do amor humano por um lugar, topofilia (TUAN, 1980), e podem se manifestar em atitudes e valores em defesa da conservação ambiental. 


\section{Conclusões}

A análise da percepção dos visitantes sobre aspectos distintos do parque demonstra que ele é importante por se constituir em opção de lazer/diversão aos seus frequentadores, sendo esse o principal fator motivacional à visitação. O significado do parque para a maioria dos visitantes entrevistados está centrado principalmente na contemplação da natureza.

A maioria considerou a vegetação importante, entretanto poucos souberam informar o nome da vegetação predominante no parque, que é a Mata Atlântica.

O parque apresentou como pontos fortes: a vegetação nativa, a beleza cênica, o teleférico e o Mirante da Santa, pois os visitantes classificaram esses atrativos como excelentes. O zoológico foi classificado por muitos como bom, apesar de que nos relatos referentes às questões abertas verificam-se críticas que levam a considerá-lo como um ponto negativo (maus tratos dos animais, falta de alimentos, recintos pequenos e com mau cheiro), além disso, outros destacaram a importância de aumentar a quantidade e diversidade de animais nos recintos (cativeiros) a fim de proporcionar mais opções de lazer e diversão.

Os equipamentos de lazer também foram considerados bons por boa parte dos entrevistados, entretanto nas questões abertas muitos visitantes relataram que o parque carece de equipamentos destinados ao lazer/diversão. Nesse sentido, vale ressaltar que o parque está localizado dentro da Área de Proteção Ambiental Morro do Urubu, uma unidade de conservação que deve compatibilizar o uso recreativo, visitação e lazer condicionado ao uso sustentável.

Desse modo, verificou-se a necessidade de interferências sensibilizadoras pautadas em atividades de educação ambiental direcionadas aos atores sociais envolvidos com o parque, pois a sensibilização quanto aos problemas ambientais se constitui no caminho que leva à conservação ambiental, pois agrega aliados na defesa do uso sustentável dos recursos da natureza.

Outros pontos considerados negativos com relação ao parque são referentes à falta de segurança e de receptividade, visto que ocorrem muitos assaltos durante as visitações. Os visitantes também classificaram tanto a segurança quanto a receptividade como ruins.

Verificou-se a presença de pertencimento ao lugar nos relatos dos entrevistados, apresentados de forma direta como sentimentos afetivos relacionados à infância.

A verificação de sentimentos de topofilia nos enunciados apresentados pelos entrevistados pode ser considerado como um ponto positivo no que se refere a relação do homem com o parque e seus atributos ambientais, visto que instiga sentimentos, que podem ser desdobrados em atitudes e valores ambientais em defesa da conservação dos recursos naturais tanto em relação ao parque em si, como além dele, perpassando pela responsabilidade 
ambiental que cada indivíduo apresenta perante os cuidados com o meio ambiente no seu dia a dia.

\section{Agradecimentos}

À Universidade Federal de Sergipe, por tornar possível o mestrado da primeira autora.

\section{Referências}

ALENCAR, E. Introdução à Metodologia de Pesquisa Social. Edgar Alencar: UFLA, 1999. 125p.

ARAÚJO, L.R.R. de; FREITAS de, D.M.A.; BRAGHINI, C.R. Ecoturismo como alternativa para o desenvolvimento sustentável da APA do Morro do UrubuAracaju (SE). Revista Brasileira de Ecoturismo, São Paulo, v.4, n. 2, 2011.

BARDIN, L. Análise de Conteúdo. Tradução Luís Antero Reto, Augusto Pinheiro. São Paulo: Edições 70, 2011. 279 p.

BARROS, M.P. de; De MUSIS, C. R. de; HORNICK, C. Parque da cidade Mãe Bonifácia, Cuiabá-MT: topofilia e amenização climática em um fragmento de cerrado urbano. Revista da Sociedade Brasileira de Arborização Urbana, Piracicaba-SP, v. 5, n. 2, p. 01-18, 2010.

DORIGO, T.A.; LAMANO-FERREIRA, A.P.N. Contribuições da Percepção Ambiental de Frequentadores sobre Praças e Parques no Brasil (2009-2013): revisão bibliográfica. Revista de Gestão Ambiental e Sustentabilidade, vol. 4, n. 3, 2015. Disponível em: http://www.revistageas.org.br/ojs/index.php/ geas/article/view/138. Acesso em: 02/10/2017.

FRANÇA, T.P.P. de; SANTOS, C.Z.A. dos; GOMES, L.J. Arborização de Aracaju: uma percepção dos seus moradores. Geografia (Londrina), v. 21, n. 2, p. 5-22, 2013. Disponível em: http://www.uel.br/revistas/uel/index.php/ geografia/article/view/9507. Acesso em: 10/11/2016.

GRAÇA, T.C.C, da. De Maçaranduba a Industrial: história e memória de um lugar. ARACAJU: Fundação Municipal de Cultura, Turismo e EsportesFUNCAJU, 2005. 90p.

HILDEBRAND, E. Avaliação econômica dos benefícios gerados pelos parques urbanos: estudo de caso em Curitiba-PR. 2001. Tese de Doutorado. Universidade Federal do Paraná. Disponível em: https://acervodigital.ufpr. br/bitstream/handle/1884/25334/T\%20-\%20HILDEBRAND,\%20ELISABETH.pdf ?sequence $=1$. Acesso em: 10/11/2016.

HO; T.L.; KOVALSYKI, B.; ZAMPRONI, K.; BIONDI, D. Percepção dos moradores sobre a arborização de ruas da região central de Mandirituba/PR. Revista da Sociedade Brasileira de Arborização Urbana, Piracicaba, v.10, n. 3, p. 14-23, 2015. 
MATOS, A.A.; GOMES, L. J.. Participação Social: A interface ausente na área de proteção ambiental Morro do Urubu, Aracaju-SE. Scientia Plena, v. 07, p. 1-11, 2011. Disponível em: file:///C:/Users/Laura\%20Gomes/Downloads/3432218-1-PB.pdf. Acesso em: 15/07/2017.

MAZZEI, K.; COLESANTI, M.M.; SANTOS, D.G. dos. Áreas verdes urbanas, espaços livres para o lazer. Revista Sociedade \& Natureza, v. 19, n. 1, 2007. http://www.seer.ufu.br/index.php/sociedadenatureza/article/view/9350. Acesso em: 11/10/2016.

RODRIGUES, A. de J. Metodologia Científica. São Paulo: Avercamp, 2006. $50 \mathrm{p}$.

SANTOS, C.Z.A.; GOMES, L.J.; FERREIRA, R. Planejamento de áreas verdes públicas: estudo de caso do município de Aracaju, Sergipe. 1. ed. Novas Edições Acadêmicas, 2016. v. 1. 132p.

SANTOS, L.I. da C.; GOMES, L.J.; GOMES, S.H.M.; SANTANA, L.L. Identificação das ações impactadas na Área de proteção Ambiental Morro do Urubu, Aracaju-SE. Scientia Plena, vol.9, n. 10, 2013. Disponível em: https://www.scientiaplena.org.br/sp/article/view/973. Acesso em: 11/10/2016.

SERGIPE. Decreto № 13.713, de 16 de junho de 1993. Institui a área de Proteção Ambiental do Morro do urubu e dá outras providências, 1993.

SILVA, D.A.; BATISTA, D.B.; BATISTA, A.C. Percepção da população quanto a arborização com mangifera indica I. (mangueira) nas ruas de Belém - PA. Revista da Sociedade Brasileira de Arborização Urbana, Piracicaba - SP, v.10, n.1, p. 1-18, 2015.

SILVA, M. do S.F.; SOUZA, R.M. Territórios Usados em áreas protegidas e Atrativos Turísticos: Exploração ou Conservação Ambiental? Revista Nordestina de Ecoturismo, Aquidabã, v. 4, n.2, outubro de 2011. Disponível em: http://sustenere.co/journals/index.php/nature/issue/view/21. Acesso em: 15/07/2017.

SOUZA, S. M. de; CARDOSO, A. de L.; SILVA, A. G. Estudo da percepção da população sobre a arborização urbana, no município de Alegre-ES. Revista da Sociedade Brasileira de Arborização Urbana, Piracicaba, v. 8, n. 2, p. 68-85, 2013.

TUAN, Y.F. Topofilia: um estudo da percepção, atitudes e Valores do Meio Ambiente. São Paulo/ Rio de Janeiro: DIFEL, 1980.

VIEZZER, J.; BIONDI, D.; BATISTA, A.C.; BRANDT, D. Perfil dos usuários e sua percepção dos elementos de composição paisagística das praças de Curitiba-PR. Revista da Sociedade Brasileira de Arborização Urbana, Piracicaba-SP, v.11, n.3, p.01-16, 2016. 